\title{
Amin Oksidaz İnhibitörleri İle Androjenlerin Kan Kolesterol Seviyesine Etkileri
}

The Effects of Amine Oxidase Inhibitors with Androgens on the Blood Cholesterol Level

\author{
fïknettin TANALP, Bilge UZALP(*)
}

Genellikle ilâç uygulamasında ilâcın en etkin olduğu alan göz önüne alınır. Diğer yandan sistemlerdeki etkileri araştırılarak, en az zarar veen çok yarar sağlanması dikkate alınır. Bu arada birden fazla ilâç uygulamada da ilâçların etkileşmesi nedeniyle amaçta ne dereceye kadar başarılı olunabileceğinin de düșünülmesi zorunluğu vardır.

Evvelce kan kolesterol seviyesine etkileri saptanmış olan erkeklik seks hormonu androjenlerin $(1,5,6)$ ve antidepresif etkili monoamin oksidaz inhibitörlerinin $(2,4)$ birlikte uygulanmasının kan kolesterol seviyesinde doğuracağı sonuçların saptanması çalışmalarımızın temelini teșkil etmiștir.

\section{DENEL K I S I M \\ M A TER Y A L}

Deneylerde 225 - 325 g ağırlığındaki, 5 - 6 aylık erkek sıçanlar kullanildi.

Monoamin oksidaz inhibitörü olarak İsokarboksazid (Marplan) ve Nialamid (Niamid), bu ilâçları çözmede propilen glikol kullanıldı.

Androjen olarak Testosteron propionat (Testoviron), seyreltmede steril nötral zeytinyağı kullanıld.

Deney sonuçları Bosch and Lomb Spectronic 20 tipi spektrofotometrede okundu.

Redaksiyona verildiği tarih : 13, Mart. 1975

(*) Tıp Bilimleri Kürsüsü, Eczacllık Fakültesi, Ankara Üniversitesi 
Deney hayvanlarının diyetinde Besi Tavuk Yemi (Pelet) No, 201 ve Yem Sanayii Laboratuvarlar için Kobay Peletleri No. 881 tipi besinden faydalanıld..

$$
\text { Y ŌNTEM }
$$

Deney hayvanları iki ay süre ile diyete alındı, bu arada ağırlıkları, kan kolesterolleri ve androjenik aktiviteleri kontrol altında tutuldu. Androjenik aktivite kontrolu Zimmermann'nn idrarda 17 . ketosteroid miktarı tayin metodu ile yapıldı (7).

Șahit deney hayvanlarının yanısıra gruplar halinde :

a) İsokarboksazidin propilen glikoldeki çözeltisi $1 \mathrm{mg} / \mathrm{kg} 2$ $\mathrm{mg} / \mathrm{kg}$ (2), $30 \mathrm{mg} / \mathrm{kg}$ dozlarda intraperitoneal yoldan erkek sıçanlara 21,30 ve 60 günlük sürelerle hergün enjekte edildi.

b) Nialamidin propilen glikoldeki çözeltisi $100 \mathrm{mg} / \mathrm{kg}$ dozda (4) intraperitoneal yolla erkek siçanlara 30 ve 60 gün uygulandı.

c) Steril nötral zeytinyağı ile dilüe edilmiş Testosteron propionat $10 \mathrm{mg} / \mathrm{kg}, 20 \mathrm{mg} / \mathrm{kg}$, (5) ve $30 \mathrm{mg} / \mathrm{kg}$ dozda intraperitoneal yolla erkek siçanlara haftada 3 defa olmak üzere zerk edildi. Uygulamaya birlikte verildiği ilâca bağlı olarak devam edildi.

d) İlâçlarn çözmede kullanılan propilen glikol ve steril nötral zeytinyağı için aynı uygulama tekrarlandı.

Kontrol ve ilâçlanmıș deney hayvanlarından, ilâçların tesir süresine bağlı olarak 21 ve 30 . günlerde ve uzun süredeki etkiyi saptayabilmek için 60 . günde kuyruk ucundan alınan kanın bekletilerek çıkarılan serumunda Leffler Metodu'na göre (3) kan kolesterol seviyesi saptand.

$$
B \cup L G \cup L A R
$$

Uygulama sonuçlarının ortalama değerleri tablo I de gösterilmiştir. Tablonun incelenmesinde görülebileceği gibi monoamin oksidaz inhibitörleri androjen ile birlikte total kan kolesterol miktarında ve ağırlıkta belirgin düşme yaparken, eriticilerden prorilen glikol kan kolesterol seviyesini negatif, steril nötral zeytinyağı ise pozitif yönde etkilemiştir. 
Monoamin oksidaz inhibitörleri kan kolesterol seviyesini düşürmüştür ki bu sonuç KOBAYASHİ ve çalıșma grubunun bulgularına uymaktadir (2).

Bunların yanısıra 21, 30 ve 60 günlük süreler ve çeşitli dozlarda uygulama sonuçlarından monoamin oksidaz inhibitörlerinin antidepresif etki süresine kadar az, sonra ise ani düșmeye sebep olduğu, uzun süreli uygulamaların da bunun dișında total kolesterol seviyesinde belirgin değișmeler yapmadı̆̆ı ve ilaç dozu ve total kan kolesterol seviyesindeki düșmenin doğru orantılı olduğu saptandı.

Testosteron propionatın kan kolesterol seviyesini düşürdügünü belirleyen bulgularımızı BERGSTRAND, AMIYYA ve ROY, SMIETANSKA ve çalışma grubu, UCHIDDA ve çalıșma grubunun araştırma sonuçları da teyit etmektedir $(1,5,6)$.

Androjenik aktivitenin de beklenildiği gibi testosteron uygulamasında arttığı görüldü.

Ayrica Kobay Peletleri No. 881 tipi besinin Besi Tavuk Yemi (Pelet) No. 201 tipi besine oranla daha az ağırlık kaybına yol açtığ1 saptandi.

Bütün uygulamalar sırasında deney hayvanlarının beden ağırlıkları kontrol altında tutularak, kontrollar, çözücü ve Testosteron propionat uygulamalarında artma, onun dışındaki uygulamalarda ise azalma olduğu saptandi.

Bulgulara bakılarak kan kolesterol seviyesinde ilâçlarin yaptığı düşmenin çözücülerle değişebileceği, kombine uygulamada ilâçların ayrı ayrı yaptıkları düşme etkisinin birbirine eklendiği, bu etkilerin kolesterol sentezinde inhibisyon veya adrenerjik mekanizmanın stimülasyonuna bağlı olabileceği sonuçları akla yakın gözükmektedir. 
Tablo I

Total Kan kolesterol seviyesi ve ağırlıktaki değișmelerin ortalamalara göre absolut ve $\%$ değerleri

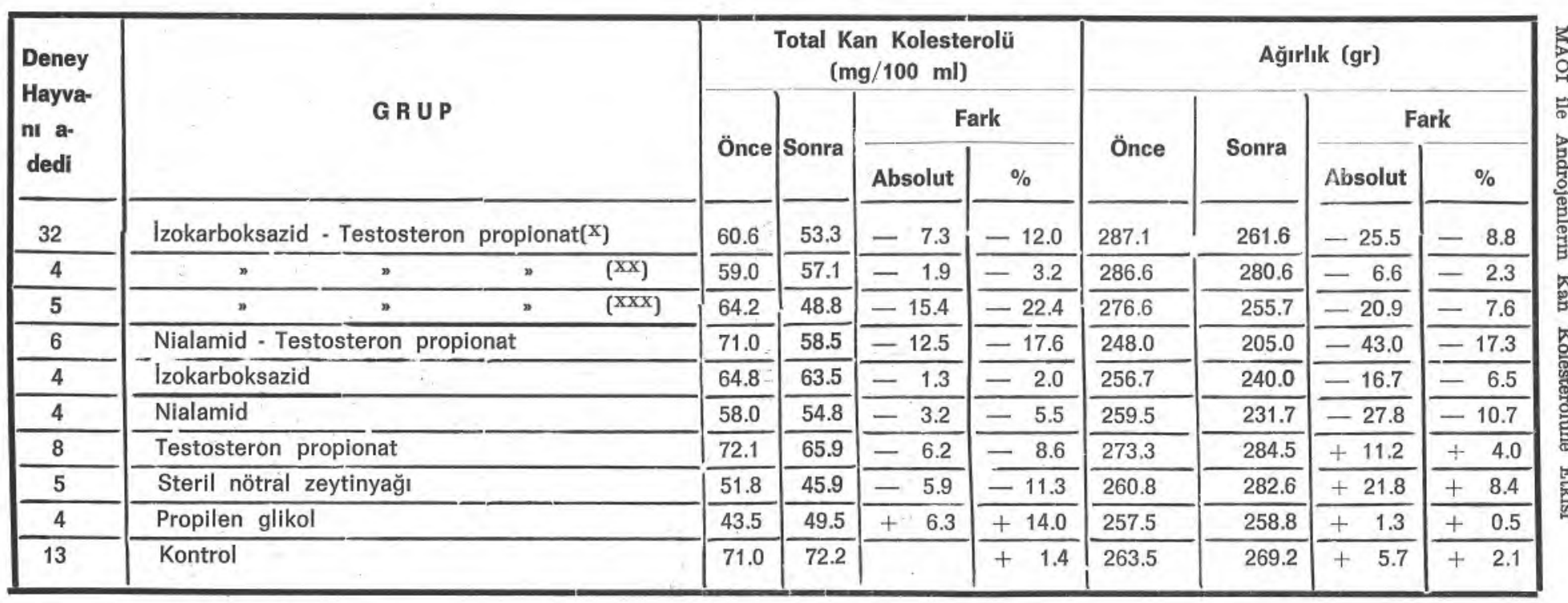

(x) Normal doz uygulaması

(Xx) Düșük

( $\mathrm{xxx}$ ) Yüksek " 


\section{Ö Z E T}

Bu çalışmada monoamin oksidaz inhibitörleri ile erkeklik seks hormonu androjenlerin birlikte uygulandıklarında erkek sıçan kan kolesterol seviyesi ve beden ağırlığına etkileri incelenmiștir.

Kan kolesterol seviyesinin saptanmasinda Leffler Metodu uygulanmıştır.

Monoamin oksidaz inhibitörü olarak Isokarboksazid ve Nialamid ve androjen olarak Testosteron propionat çeşitli doz ve sürelerle erkek sıçanlara uygulandığında kan kolesterol seviyelerinde düşme ve ağırlıklarında azalma tesbit edilmiștir.

$\mathrm{Bu}$ arada çözücülerinde konu itibariyle etkileri incelenmiş ve kan kolesterol seviyesindeki değişmelerin fizyolojik nedenleri tartışılmıştır.

\section{S U M M A R Y}

In this study, the effects of monoamine oxidase inhibitors and male sex hormone androgens combination on the blood cholesterol level and the body weights of adult male rats were investigated.

Leffler Method was used for the determination of the blood cholesterol level.

The blood cholesterol level and the body weights of adult male rats were decreased when Isocarboxazide and Nialamide as monoamine oxidase inhibitors and Testosterone propionate as androgen were administered during a period of 21,30 and 60 days.

In the meantime effects of the solvents of monoamine oxidase inhibitors and androgen on the blood cholesterol level and the body weight were investigated.

The alterations in the body weight and the blood cholesterol level were discussed from the standpoint of physiology. 


\section{I T E R A T Ü R}

1. Ben-David, B., Dikstein, S., Bismuth, G. and Sulman, F. G., Prac. Soc. Exp. Bicl. Med, 125, 1136 - 40 (1967).

2. Kobayashi, M., et al., J. Nihon Univ. Sch. Dent, 7, 120 - 8 (1965).

3. Mark, D. D., Zimmer, A., - Atlas of Clinical Laboratory Procedures, 1, 55-61, Mc Graw - Hill Book Comp., London (1967).

4. Mattila, M. and Torsti, P., Ann. Med. Exp. Fenn., 44, 397 - 400 (1966).

5. Smietanska, Z., Ciswicka - Sznajderman, M., Pol. Med. J., 5, 1038 - 1048 (1966).

6. Uchida, K., Kadowaki, M., Miyata, K. and Miyake, T, Endocrinol. Japan, 16 (1) $211-214$ (1969).

7. Yenson, M., -Tıpsal ve Klinik Kimyasal Laboratuvar Çalıșmaları, 1, 188, Sulhi Garan Matbaası Varisleri Kol. Ști., Istanbul (1971). 